\title{
INFLUENCIA DEL pH SOBRE LA DIGESTIÓN ANAEROBIA DE BIORRESIDUOS DE ORIGEN MUNICIPAL
}

\section{INFLUENCE OF pH ON ANAEROBIC DIGESTION OF MUNICIPAL BIO-WASTES}

\author{
Brayan Alexis Parra-Orobio ${ }^{1}$, Patricia Torres-Lozada ${ }^{2}$, Luis Fernando Marmolejo-Rebellón ${ }^{3}$, Lina Marcela Cárdenas-Cleves ${ }^{4}$, \\ Carlos Vásquez-Franco ${ }^{5}$, Wilmar Alexander Torres-López ${ }^{6}$, José Abdón Ordóñez-Andrade ${ }^{7}$
}

${ }^{1}$ Ing. Sanitario, Escuela de Ingeniería de Recursos Naturales y del Ambiente-EIDENAR, Universidad del Valle. Calle 13 \# $100-$ 00, Cali, Colombia. brayan.parra@correounivalle.edu.co; ${ }^{2}$ Ing. Sanitaria, M.Sc., Ph.D., Prof. Titular, Escuela de Ingeniería de Recursos Naturales y del Ambiente-EIDENAR, Universidad del Valle, Calle 13 \# 100-00, Cali-Colombia, e-mail: patricia. torres@correounivalle.edu.co; ${ }^{3}$ Ing. Sanitario, M.Sc., Ph.D. Prof. Asistente. Escuela de Ingeniería de Recursos Naturales y del Ambiente-EIDENAR, Universidad del Valle. Calle 13 \# 100-00, Cali, Colombia. luis.marmolejo@correounivalle.edu.co; ${ }^{4}$ Estudiante de Ingeniería Sanitaria, Escuela de Ingeniería de Recursos Naturales y del Ambiente-EIDENAR, Universidad del Valle. Calle 13 \# 100-00, Cali, Colombia. lina.cardenas.cleves@correounivalle.edu.co; ${ }^{5}$ Estudiante de Ingeniería Sanitaria, Escuela de Ingeniería de Recursos Naturales y del Ambiente-EIDENAR, Universidad del Valle. Calle 13 \# 100-00, Cali, Colombia. carlos.vasquez@correounivalle.edu.co; ${ }^{6}$ Estadístico, Prof. Auxiliar, Escuela de Estadística, Universidad del Valle. Calle 13 \# 100-00, Cali, Colombia. alexandertor@gmail.com; ${ }^{7}$ Ing. Sanitario, Ing. Industrial, Magíster en Ingeniería Ambiental, Departamento de Gestión del Agua Urbana, Universität Kassel. Mönchebergstraße 19, 34125, Kassel, Alemania. joseabdonordonez@hotmail.com

Rev. U.D.C.A Act. \& Div. Cient. 17(2): 553-562, Julio-Diciembre, 2014

\section{RESUMEN}

Los biorresiduos de origen municipal-BOM, se caracterizan por su alto contenido de materia orgánica, humedad y nutrientes, además de ser residuos fácilmente acidificables, lo que los convierte en una fuente contaminante cuando se disponen inadecuadamente. La digestión anaerobia-DA es una alternativa tecnológica para el control de la contaminación de los BOM y la obtención de una fuente de energía renovable, como el metano; sin embargo, variables, como el pH, pueden afectar el proceso. Este estudio evaluó, a escala de laboratorio, mediante ensayos de Potencial Bioquímico de Metano-PBM, a una temperatura de $30^{\circ} \mathrm{C}$, durante 40 días, la influencia del $\mathrm{pH}$ sobre la DA de BOM. Los valores de $\mathrm{pH}$ del sustrato variaron entre 5,5 a 8,0 unidades, utilizando como inóculo lodo, proveniente de la biodigestión anaerobia de lodos, de una planta de tratamiento de aguas residuales domésticas. Se evidenció que los $\mathrm{pH}$ ácidos correspondientes a 5,5 y 6,0 unidades, presentaron la menor producción de metano, del orden de 70,0 y $71,0 \mathrm{mLCH}_{4} * \mathrm{gSV}^{1}$, respectivamente, mientras que los $\mathrm{pH}$ cercanos a la neutralidad, lograron los mejores resultados, siendo la producción a un $\mathrm{pH}$ de 7,0 unidades la mayor, la cual, fue $126,0 \mathrm{mLCH}_{4} * \mathrm{gSV}^{-1}$. Los resultados están acordes con el comportamiento de la capacidad buffer, que fue más adecuada, entre 7,0 y 8,0 unidades, garantizando estabilidad del proceso anaerobio y evitando así la ocurrencia de fenómenos de inhibición. Para lograr estos niveles de $\mathrm{pH}$, se hace necesario adicionar un alcalinizante, debido a las características ácidas de los BOM.

Palabras clave: Biodegradabilidad anaerobia, capacidad buffer, potencial bioquímico de metano, residuos sólidos.

\section{SUMMARY}

Municipal bio-wastes-MBW are characterized by their high content of organic matter, humidity, nutrients, and additionally are wastes easily acids, which makes them a source of pollution when are improperly disposed. Anaerobic digestion-AD is a technological alternative for MBW pollution control as well as for methane production as a renewable energy source; however, parameters such as $\mathrm{pH}$ can affect the process. This study evaluated at laboratory scale thought Biochemical Potential Methane-BPM assays at a temperature of $30^{\circ} \mathrm{C}$ during 40 days, the influence of $\mathrm{pH}$ on the MBW-AD. The $\mathrm{pH}$ values tested ranged from 5.5 to 8.0 units, using as inoculum sludge coming from the sludge anaerobic digestion of a domestic wastewater treatment plant. It was noticed that the acid $\mathrm{pH}$ between 5.5 and 6.0 units had the lowest methane production, 70.0 and $71.0 \mathrm{mLCH}_{4} * \mathrm{gVS}^{-1}$ 
respectively; while $\mathrm{pH}$ values near to the neutrality achieved the best results, being the highest production of methane corresponding to a $\mathrm{pH}$ of 7.0 units, reaching a value of $126.0 \mathrm{mLCH}_{4} * \mathrm{gVS}^{-1}$. Similarly, it was found that $\mathrm{pH}$ values from 7.0 to 8.0 units had the best buffer capacity, ensuring stability of the anaerobic process and avoiding inhibition phenomena. To achieve this condition, it is necessary to apply $\mathrm{pH}$ adjust due to the acid characteristics of the MBW.

Key words: Anaerobic biodegradability, biochemical potential methane, buffer capacity, solid wastes.

\section{INTRODUCCIÓN}

En países en desarrollo, los biorresiduos de origen municipal-BOM representan la mayor fracción de los residuos sólidos municipales-RSM (TWB, 2012), cuya gestión depende de factores locales, como la composición y la calidad de los residuos, los sistemas de recolección, las condiciones climáticas y el potencial de utilización de los productos derivados de las opciones de aprovechamiento, entre otros, siendo el compostaje y la digestión anaerobia-DA, las opciones tecnológicas más utilizadas (Angelidaki et al. 2003).

La DA ha tomado gran relevancia, debido a que es una fuente de energía renovable, que responde a la demanda de un modelo sostenible de progreso, que no impacte negativamente a las generaciones futuras (Aguilar et al. 2009). En la DA, microorganismos específicos intervienen en cada una de las etapas de degradación y el proceso, en general, es afectado por una serie de factores ambientales y operacionales (Acosta \& Abreu, 2005).

El pH juega un papel importante, ya que está asociado a la ocurrencia de fenómenos de acidificación, que afectan negativamente el proceso (Torres \& Pérez, 2008); en el caso de los BOM, están compuestos, principalmente, por residuos de alimentos, los cuales, se caracterizan por humedades superiores a $70 \%$ y $\mathrm{pH}$ ácido.

Aunque autores, como Buenrostro et al. (2000) afirman que la DA es más eficiente a valores de $\mathrm{pH}$ cercanos a la neutralidad, diferentes estudios sobre la influencia del $\mathrm{pH}$, indican que no se puede generalizar, debido a aspectos, como las características fisicoquímicas del sustrato, que pueden aportar capacidad buffer (Dinamarca et al. 2003) y a que cada grupo microbiano implicado en la degradación anaerobia tiene un rango de $\mathrm{pH}$ óptimo específico (Angelidaki et al. 2003). Angelidaki et al. (2009) afirman que la DA, se puede dar en un $\mathrm{pH}$ entre 5,5 y 6,5 unidades, mientras que, según Acosta \& Abreu (2005), a pH entre 8,2 a 8,4 unidades el proceso ocurre sactifactoriamente.

Debido a que del control de procesos de acidificación de- pende la mayor o menor producción de metano (Buenrostro et al. 2000) y a que cada sustrato presenta características específicas, en este estudio, se evaluó, a escala de laboratorio, mediante ensayos de Potencial Bioquímico de Metano-PBM, el efecto del $\mathrm{pH}$ sobre la producción de metano a partir de la digestión anaerobia de biorresiduos de origen municipal.

\section{MATERIALES Y MÉTODOS}

El estudio fue realizado en el Laboratorio de Biotecnología Ambiental de la Universidad del Valle, Sede Meléndez de la ciudad de Cali, Colombia, a una altitud de 970 m.s.n.m., con una temperatura promedio de $23,6^{\circ} \mathrm{C}$.

Los BOM procedieron de una planta de manejo de residuos sólidos-PMRS, de un municipio colombiano, en el que se realiza una gestión integral de los residuos sólidos municipales, que incluye separación en la fuente y recolección selectiva. Los BOM estuvieron almacenados por cuatro días en las viviendas, previo a su recolección (Oviedo et al. 2014).

El programa de muestreo y de caracterización de los BOM correspondió a cinco muestras y se ejecutó de acuerdo con Sakurai (2000). La composición física consideró las siguientes categorías: i) residuos de comida: alimentos procesados y sin procesar; ii) papel y cartón; iii) poda y jardín y, iv) impropios: plástico, metales, caucho, entre otros (Oviedo et al. 2014).

El BOM fue caracterizado, de acuerdo con APHA (2005), ICONTEC (2004) e ICONTEC (2009), en términos de las variables $\mathrm{pH}$ (Unidades), alcalinidad total-AT y bicarbonáticaATB $\left(\mathrm{mgCaCO}_{3} * \mathrm{~L}^{-1}\right)$, ácidos grasos volátiles-AGV's $\left(\mathrm{mg}^{*} \mathrm{~L}^{-1}\right)$, ácido acético (\%), ácido propiónico (\%), ácido butírico (\%), humedad (\%), carbono orgánico total y oxidable (\%), UV $\mathrm{UV}_{254}$ $\left(\mathrm{cm}^{-1}\right)$, DQO total y filtrada $\left(\mathrm{mg}^{*} \mathrm{~L}^{-1}\right), \mathrm{DBO}_{5}\left(\mathrm{mg}^{*} \mathrm{~L}^{-1}\right)$, nitrógeno total (\%), nitrógeno amoniacal $\left(\mathrm{mg}^{*} \mathrm{~L}^{-1}\right)$, celulosa $(\%)$, almidón (\%), lignina (\%), extracto etéreo (\%), proteínas (\%), carbohidratos (\%), fibra cruda (\%), hidrógeno (\%), oxígeno (\%), sólidos totales-ST y volátiles-SV $\left(\mathrm{mg}^{*} \mathrm{~L}^{-1}\right)$, calcio $\left(\mathrm{mg}^{*} \mathrm{~L}^{-1}\right)$, potasio $\left(\mathrm{mg}^{*} \mathrm{~L}^{-1}\right)$, magnesio $\left(\mathrm{mg}^{*} \mathrm{~L}^{-1}\right)$, cobre $\left(\mathrm{mg}^{*} \mathrm{~L}^{-1}\right)$, zinc $\left(\mathrm{mg}^{*} \mathrm{~L}^{-1}\right)$, hierro $\left(\mathrm{mg}^{*} \mathrm{~L}^{-1}\right)$, manganeso $\left(\mathrm{mg}^{*} \mathrm{~L}^{-1}\right)$, aluminio $\left(\mathrm{mg}^{*} \mathrm{~L}^{-1}\right)$, cobalto $\left(\mathrm{mg}^{*} \mathrm{~L}^{-1}\right)$, molibdeno $\left(\mathrm{mg}^{*} \mathrm{~L}^{-1}\right)$ y níquel $\left(\mathrm{mg}^{*} \mathrm{~L}^{-1}\right)$.

Como inóculo para los ensayos de PBM, se empleó lodo activo del digestor anaerobio, de una Planta de Tratamiento de Aguas Residuales municipales, que fue caracterizado en términos de $\mathrm{pH}, \mathrm{AT}$, ATB, AGV's, sólidos totales y volátiles (Field, 1987; APHA, 2005). El número de muestras caracterizadas fue de cinco.

Las muestras de $\mathrm{BOM}$ e inóculo, se preservaron durante menos de 7 días, a una temperatura no mayor a $4^{\circ} \mathrm{C}$, con el 
fin de garantizar la preservación de sus propiedades, tanto para los análisis fisicoquímicos como para los ensayos de DA, según las recomendaciones de Sandoval et al. (2007). Los resultados fueron procesados empleando métodos estadísticos descriptivos.

Previo a los ensayos de PBM, a los BOM se les retiraron los materiales que no presentaban características de biorresiduos, como material inerte: piedras, metal, carbón y hueso, y material de lenta degradación: papel, cartón y plástico Mukherjee et al. (2008) y, posteriormente, fueron sometidos a un proceso de trituración, según lo sugerido por Sharma et al. (1988), empleando una procesadora de alimentos industrial CB15 Waring Commercial, a la velocidad estándar del equipo, que corresponde a $15800 \mathrm{rpm}$, durante un minuto.

La cuantificación de biogás, se realizó mediante la técnica manométrica de ensayos PBM, empleando el sistema OXITOP (Figura 1), el cual, es un equipo de monitoreo de presión, que consta de un reactor de $250 \mathrm{~mL}$, una cabeza de medición que se inserta en la "boca" de los reactores y un controlador, que usa una interface infrarroja, para transferir los datos.

Los ensayos, se realizaron a una temperatura controlada de $30 \pm 0,5^{\circ} \mathrm{C}$, para garantizar un rango mesofilico, en una incubadora WTW TS 606-G/2-i, con agitación manual intermitente (Aquino et al. 2007), durante 40 días, efectuando mediciones cada seis horas. El volumen útil utilizado fue de $200 \mathrm{~mL}$, dejando un espacio de $50 \mathrm{~mL}$, para el almacena- miento del biogás que se produce, de acuerdo a las recomendaciones de Torres \& Pérez (2010).

Para mantener condiciones estables en los ensayos PBM, se empleó una solución de macro y micronutrientes (Torres \& Pérez, 2010) y se acondicionó el pH, con soluciones de Na$\mathrm{HCO}_{3}$ al 4,0\% y $\mathrm{HCl} 0,1 \mathrm{~N}$. Para garantizar que la medición manométrica correspondiera en su mayoría a metano, se procedió a capturar el dióxido de carbono, a través de perlas de $\mathrm{NaOH}$, validando los resultados por cromatografía de gases, en un cromatógrafo GC2014.

Las ecuaciones que se describen en la tabla 1 permitieron determinar el volumen de metano y DE PBM, a condiciones estándar-CE, siguiendo las sugerencias de Aquino et al. (2007) y Giménez et al. (2012), donde se considera la proporción de metano disuelto, la producción teórica y el Índice de Biodegradabilidad-\%B y se determinó de acuerdo a Sobotka et al. (1983).

La relación sustrato-inóculo-S/I (gSTV*gSTV ${ }^{1}$ ) establecida fue 1,0, de acuerdo a lo sugerido por Raposo et al. (2006). La figura 1 muestra los detalles de la unidad experimental y el esquema del experimento; cada una de las unidades experimentales contó con su respectivo duplicado y con un control que correspondió al inóculo, más agua destilada. Para determinar el efecto del factor evaluado, se aplicó un análisis de varianza, también conocido como ANOVA, donde la variable respuesta fue el PBM; el análisis estadístico, se realizó empleando el paquete estadístico R i386 3.0.2.

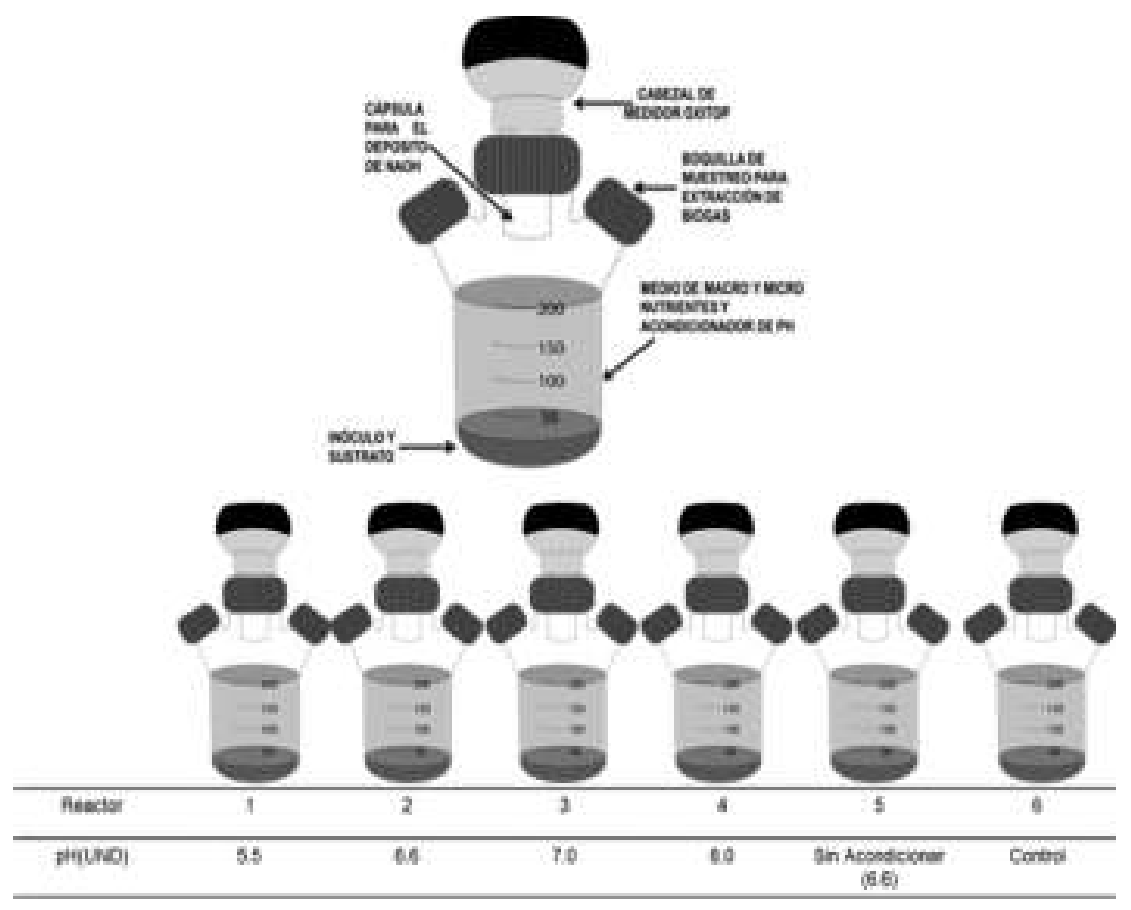

Figura 1. Esquema de la unidad experimental. 
Tabla 1. Ecuaciones para determinar el PBM, a través del método manométrico.

\begin{tabular}{|c|c|c|}
\hline Ecuación & Parámetro & Finalidad \\
\hline 1. $n_{C H 4}=\frac{\Delta P * V l}{R * T_{e}}$ & \multirow{12}{*}{ 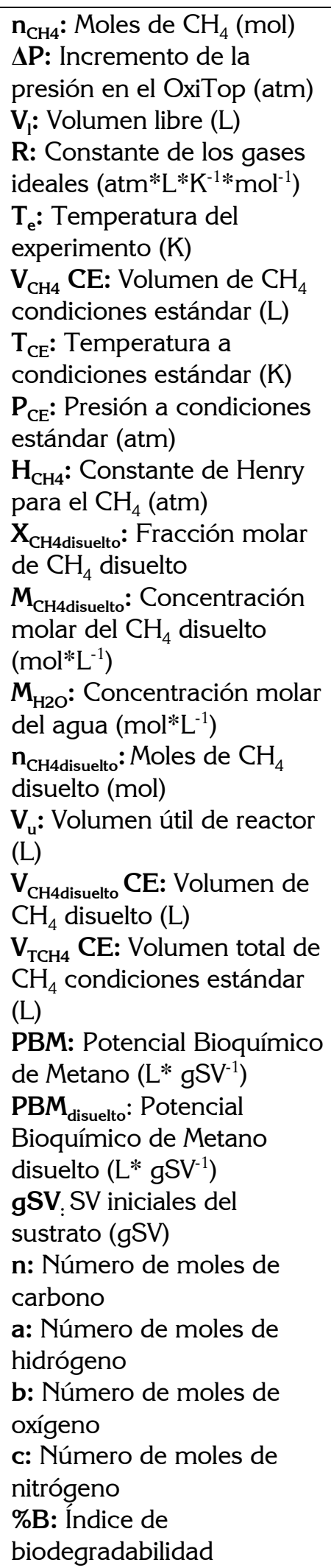 } & \multirow{2}{*}{$\begin{array}{l}\text { 1- 2. Determinar el } \\
\text { volumen de metano a } \\
\text { condiciones estándar }\end{array}$} \\
\hline 2. $V_{C H 4} C E=\frac{n_{C H 4} * R * T_{C E}}{P_{C E}}$ & & \\
\hline 3. $H_{C H 4}=10\left(\frac{-675.74}{T_{e}}+6.88\right)$ & & \multirow{5}{*}{$\begin{array}{l}\text { 3-7. Determinar } \\
\text { volumen de metano } \\
\text { disuelto }\end{array}$} \\
\hline 4. $X_{C H 4 \text { disuelto }}=\frac{\Delta P}{H_{C H 4}}$ & & \\
\hline 5. $M_{C H 4 \text { disuelto }} \frac{M_{H 2 O} * X_{C H 4 d i s u e l t o}}{1-X_{C H 4 d i s u e l t o}}$ & & \\
\hline 6. $n_{\text {CH4disuelto }}=M_{\text {CH4disuelto }} * V_{u}$ & & \\
\hline 7. $V_{C H 4 \text { disuelto }} C E=\frac{n_{C H 4 \text { disuelto }} * R * T_{e}}{\Delta P}$ & & \\
\hline 8. $V_{T C H 4} C E=V_{C H 4} C E+V_{C H 4 d i s u e l t o} C E$ & & $\begin{array}{l}\text { 8. Determinar volumen } \\
\text { total de metano en } \\
\text { condiciones estándar }\end{array}$ \\
\hline 9. $P B M=\frac{V_{T C H 4 C E}}{g S V}$ & & $\begin{array}{l}\text { 9-10. Determinar el } \\
\text { Potencial Bioquímico }\end{array}$ \\
\hline 10.PBM $M_{\text {disuelto }}=\frac{V_{C H 4 \text { disuelto }}}{g S V}$ & & $\begin{array}{l}\text { de Metano total y } \\
\text { disuelto }\end{array}$ \\
\hline 11.PBM $M_{\text {teorico }}=\frac{22.4\left(\frac{n}{2}+\frac{a}{8}-\frac{b}{4}-\frac{3 c}{8}\right) * 1000}{12 n+a+16 b+14 c}$ & & $\begin{array}{l}\text { 11. Determinar el } \\
\text { Potencial Bioquímico } \\
\text { de Metano Teórico a } \\
\text { CE }\end{array}$ \\
\hline $12 \% B=\frac{P B M}{P B M_{\text {teorico }}}$ & & $\begin{array}{l}\text { 12. Determinar el } \\
\text { Índice de } \\
\text { Biodegradabilidad }\end{array}$ \\
\hline
\end{tabular}


Al inicio y finalización de los ensayos de PBM, en cada una de las unidades experimentales, se midió pH, AT, ATB y AGV's y se determinó el Índice AI/AP, que es la relación entre la alcalinidad, debida a los AGV y la alcalinidad bicarbonática, como se indica en la ecuación 13 (Torres \& Pérez, 2008).

$$
\frac{A I}{A P}=\frac{A T-A T B}{A T B} \text { Ec. } 13
$$

Donde AI/AP es el índice de alcalinidad; AT es la alcalinidad total $\left(\mathrm{mgCaCO}_{3} * \mathrm{~L}^{-1}\right)$ y ATB es la alcalinidad bicarbonática $\left(\mathrm{mgCaCO}_{3} * \mathrm{~L}^{-1}\right)$.

\section{RESULTADOS Y DISCUSIÓN}

La composición física de los BOM mostró que, 93,13\%, corresponde a residuos de comida, de los cuales, el 91,25\%, son alimentos sin procesar y 1,88\%, alimentos procesados. En cuanto a los alimentos sin procesar, predominaron cáscaras de frutas y de vegetales, principalmente, plátano, naranja, cebolla, yuca, maracuyá, alverja, frijol y maíz; en general, estos residuos se caracterizan por contener materia orgánica de rápida degradación, características identificadas por Oviedo et al. (2014), en estudios previos.

La tabla 2 muestra los resultados de los análisis fisicoquímicos.

Los valores de pH, AT, ATB y AGV's son típicos de residuos rápidamente acidificables (Li et al. 2010); los bajos valores de $\mathrm{pH}$ están ligados al aumento de la producción de AGV's, por la descomposición de los BOM y a la ausencia de ATB. Los AGV's están asociados a ácidos grasos de cadena larga o ramificada, lo que puede prolongar los tiempos de hi-

Tabla 2. Caracterización fisicoquímica de los BOM.

\begin{tabular}{|c|c|c|c|}
\hline Parámetro & Valor (Promedio) & Parámetro & Valor (promedio) \\
\hline $\mathrm{pH}$ (unidades) & $5,54 \pm 0,06$ & Lignina & $1,20 \pm 2,16$ \\
\hline Humedad (\%) & $76,74 \pm 3,16$ & Extracto etéreo (\%) & $0,96 \pm 0,46$ \\
\hline AT $\left(\mathrm{CaCO}_{3} \mathrm{mg}^{*} \mathrm{~L}^{-1}\right)$ & $4447,06 \pm 1248,79$ & Proteínas (\%) & $2,70 \pm 4,95$ \\
\hline ATB $\left(\mathrm{CaCO}_{3} \mathrm{mg}^{*} \mathrm{~L}^{-1}\right)$ & - & Carbohidratos (\%) & $9,60 \pm 0,56$ \\
\hline $\mathrm{AGV}\left(\mathrm{CaCO}_{3} \mathrm{mg}^{*} \mathrm{~L}^{-1}\right)$ & $10595,52 \pm 1086,40$ & Fibra cruda (\%) & $2,67 \pm 0,39$ \\
\hline Ácido acético (\%) & $<0,0001$ & Hidrógeno* & $4,82 \pm 0,35$ \\
\hline Ácido propiónico (\%) & $<0,0001$ & Oxígeno* & $32,57 \pm 0,98$ \\
\hline Ácido butírico (\%) & $<0,0001$ & Sólidos totales $\left(\mathrm{mg}^{*} \mathrm{~L}^{-1}\right)$ & $113036,67 \pm 15240,67$ \\
\hline $\mathrm{COT}^{*}(\%)$ & $37,98 \pm 2,34$ & Sólidos volátiles $\left(\mathrm{mg}^{*} \mathrm{~L}^{-1}\right)$ & $93016,67 \pm 28527,54$ \\
\hline Carbono oxidable* (\%) & $5,70 \pm 1,74$ & Calcio $\left(\mathrm{mg}^{*} \mathrm{~L}^{-1}\right)$ & $4174,10 \pm 856,01$ \\
\hline $\operatorname{UV}_{254}\left(\mathrm{~cm}^{-1}\right)$ & $>3,30$ & Potasio $\left(\mathrm{mg}^{*} \mathrm{~L}^{-1}\right)$ & $2637,39 \pm 65,85$ \\
\hline $\mathrm{DQO}$ total $\left(\mathrm{mg}^{*} \mathrm{~L}^{-1}\right)$ & $137839,06 \pm 72267,12$ & Magnesio $\left(\mathrm{mg}^{*} \mathrm{~L}^{-1}\right)$ & $175,80 \pm 69,85$ \\
\hline $\mathrm{DQO} \mathrm{O}_{\text {filtrada }}\left(\mathrm{mg}^{*} \mathrm{~L}^{-1}\right)$ & $35604,49 \pm 3600,12$ & Cobre $\left(\mathrm{mg}^{*} \mathrm{~L}^{-1}\right)$ & $0,57 \pm 2,5$ \\
\hline $\mathrm{DBO}_{5}\left(\mathrm{mg}^{*} \mathrm{~L}^{-1}\right)$ & $45333,33 \pm 1800,25$ & Zinc & $4,22 \pm 1,5$ \\
\hline Nitrógeno total* (\%) & $1,70 \pm 1,02$ & Hierro & $134,29 \pm 23,12$ \\
\hline $\begin{array}{l}\text { Nitrógeno amoniacal }\left(\mathrm{mg}^{*} \mathrm{~L}^{-}\right. \\
\text {1) }\end{array}$ & $324,45 \pm 55,17$ & Manganeso & $4,01 \pm 25,15$ \\
\hline $\begin{array}{l}\text { Nitrógeno amoniacal no } \\
\text { ionizado }\left(\mathrm{mg}^{*} \mathrm{~L}^{-1}\right)\end{array}$ & $0,13 \pm 0,05$ & Aluminio & $0,0 \pm 0,0$ \\
\hline $\begin{array}{l}\text { Nitrógeno amoniacal ion } \\
\text { amonio }\left(\mathrm{mg}^{*-1} \mathrm{~L}^{-1}\right)\end{array}$ & $324,32 \pm 48,21$ & Cobalto $\left(\mathrm{mg}^{*} \mathrm{~L}^{-1}\right)$ & $<1,0$ \\
\hline Celulosa (\%) & $1,47 \pm 3,58$ & Molibdeno $\left(\mathrm{mg}^{*} \mathrm{~L}^{-1}\right)$ & $<1,0$ \\
\hline Almidón (\%) & $<0,1$ & Níquel $\left(\mathrm{mg}^{*} \mathrm{~L}^{-1}\right)$ & $<1,0$ \\
\hline
\end{tabular}

*En base seca; COT: Carbono orgánico total 
drólisis y de adaptación microbiana (Sundberg et al. 2011), por lo que es recomendable acondicionar los BOM con un alcalinizante, que aporte capacidad buffer, para neutralizar la acidez y favorecer la DA de los BOM (Abdulkarim \& Abdullahi, 2010).

El alto contenido de humedad de los BOM puede favorecer la etapa de hidrólisis, que ocurre como etapa inicial del proceso de DA (González et al. 2008); sin embargo, la baja relación $\mathrm{DQO}$ filtrada/DQOtotal indica la predominancia de material particulado y puede ser desfavorable para esta etapa del proceso, incrementando el tiempo de retención de sólidos -TRS, como lo evidenció Castells (2012), en estudios de DA de BOM. Las variables $\mathrm{UV}_{254}$, COT, DQO, DBO5 y SV demuestran el alto contenido de materia orgánica, lo cual, está asociado con la composición física y fina de los BOM (Li et al. 2010).

El pH influye sobre la forma predominante del nitrógeno, siendo un factor importante en los procesos biológicos, debido a la probable ocurrencia de fenómenos de inhibición de la actividad microbiana (Dinamarca et al. 2003). En los BOM predominó el Namoniacal en la forma de ion amonio, con una concentración de $324.3 \mathrm{mg}^{*} \mathrm{~L}^{-1}$, mientras que la de Namoniacal no ionizado, que es la forma más tóxica, fue $0.13 \mathrm{mg}^{*} \mathrm{~L}^{-1}$. Desde el punto de vista del aporte a la capacidad buffer, autores como Parawira et al. (2004) recomiendan una concentración del orden de $1100 \mathrm{mg}^{*} \mathrm{~L}^{-1}$, para la adecuada DA, de este tipo de residuos, lo que ratifica la necesidad de usar un alcalinizante, durante el proceso.

Los BOM presentaron una relación C/N, entre 20 y 30, lo cual, tiene efectos positivos sobre la DA (Buenrostro et al. 2000); este valor puede estar relacionado con el alto contenido de proteína, por la presencia de fríjoles y de lentejas. La relación SV/ST también ratifican el alto contenido de materia orgánica, resultados que son similares a los encontrados por Chen et al. (2010).

Generalmente, la celulosa y la lignina de los BOM, se relacionan con la presencia de papel, pañales desechables y residuos de poda (Delfín \& Durán, 2003) y son superiores al $33 \%$ y $10 \%$, respectivamente, cuando no existe una efeciente separación en la fuente (Peres et al. 1992); los valores obtenidos ratifican que estas prácticas son adecuadas. El contenido de almidón también es bajo, posiblemente, por el almacenamiento de 3 a 4 días en las viviendas que la fermentación y la formación de azúcares. Otros compuestos, como extracto etéreo, fibra cruda, proteínas y carbohidratos, se encontraron en niveles similares a los reportados por Chen et al. (2010), para este tipo de residuos.

Las concentraciones de metales importantes para el proceso de DA de BOM, se encontraron en el rango que no causan inhibición al proceso (Almeida et al. 2011), siendo el calcio y el potasio los más elevados; el alto contenido de calcio puede estar relacionado a la presencia de cáscaras de huevo y, el de potasio ligado, con las cáscaras de plátano (Oviedo et al. 2014).

Los valores de $\mathrm{pH}, \mathrm{AT}$, ATB y AGV's, para el inóculo que fueron de 7,25 unidades, $6270,40 \mathrm{mg}^{*} \mathrm{~L}^{-1}, 3390,34 \mathrm{mg}^{*} \mathrm{~L}^{-}$ ${ }^{1}$ y $1033,53 \mathrm{mg}^{*} \mathrm{~L}^{-1}$, respectivamente y se encuentran entre valores característicos para lodos de digestores de PTAR municipales (Raposo et al. 2006). Las concentraciones de AT y ATB indican que el inóculo tiene una buena capacidad buffer para la DA. El contenido de ST de $74090 \mathrm{mg}^{*} \mathrm{~L}^{-1}$ y de SV $28252,85 \mathrm{mg}^{*} \mathrm{~L}^{-1}$, indica una baja presencia de biomasa activa y el valor es inferior a los reportados por Raposo et al. (2006).

Evaluación del pH en la DA de los BOM: La figura 2 muestra el PBM de cada una de las unidades experimentales - UE evaluadas. En general, se puede apreciar que, aunque la relación SV/ST del inóculo fue baja, los BOM proporcionaron condiciones favorables para la producción de metano, ya que todas las UE, independiente del $\mathrm{pH}$, registraron valores del PBM por encima del control; la producción de metano osciló entre 70,0 y $126,0 \mathrm{mLCH}_{4} * \mathrm{gSV}^{-1}$.

Se observa que al día 30 del ensayo, en todas las UE, la producción de $\mathrm{CH}_{4}$ fue superior al $85 \%$ del total, con excepción de la UE en que el $\mathrm{pH}$ inicial fue 5,5 unidades, en la cual, la producción alcanzó sólo el $47 \%$. Otro aspecto a destacar es que, a medida que el pH aumentó, el tiempo de adaptación de la biomasa al sustrato fue menor; los menores tiempos correspondieron a valores de $\mathrm{pH}$ de 6,6 y 8,0 unidades con 8 y 13 días, respectivamente, mientras para los $\mathrm{pH}$ de 5,5 y 6,0 unidades, el tiempo aumentaron a 25 y 17 días, respectivamente.

La tabla 3 presenta los resultados de PBM total, disuelto y teórico, los porcentajes de metano y el Índice de Biodegradabilidad-\%B.

Aunque el análisis estadístico, mediante la prueba ANOVA, con un $p<0,1$, indicó que no existieron diferencias estadísticas entre los $\mathrm{pH}$ evaluados y el PBM, esta variable tiene gran influencia sobre la actividad de los microorganismos que intervienen en cada una de las fases, principalmente, en la producción de metano, a cargo de los microorganismos más sensibles, que son las arqueas metanogénicas (Angelidaki et al. 2003).

Los resultados del PBM muestran que el pH neutro fue el de mayor producción de metano y que los $\mathrm{pH}$ cercanos a 6,6 y 8,0 unidades fueron más favorables que los de 5,5 y 6,0 unidades, lo que coincide con estudios, como el de Veeken 


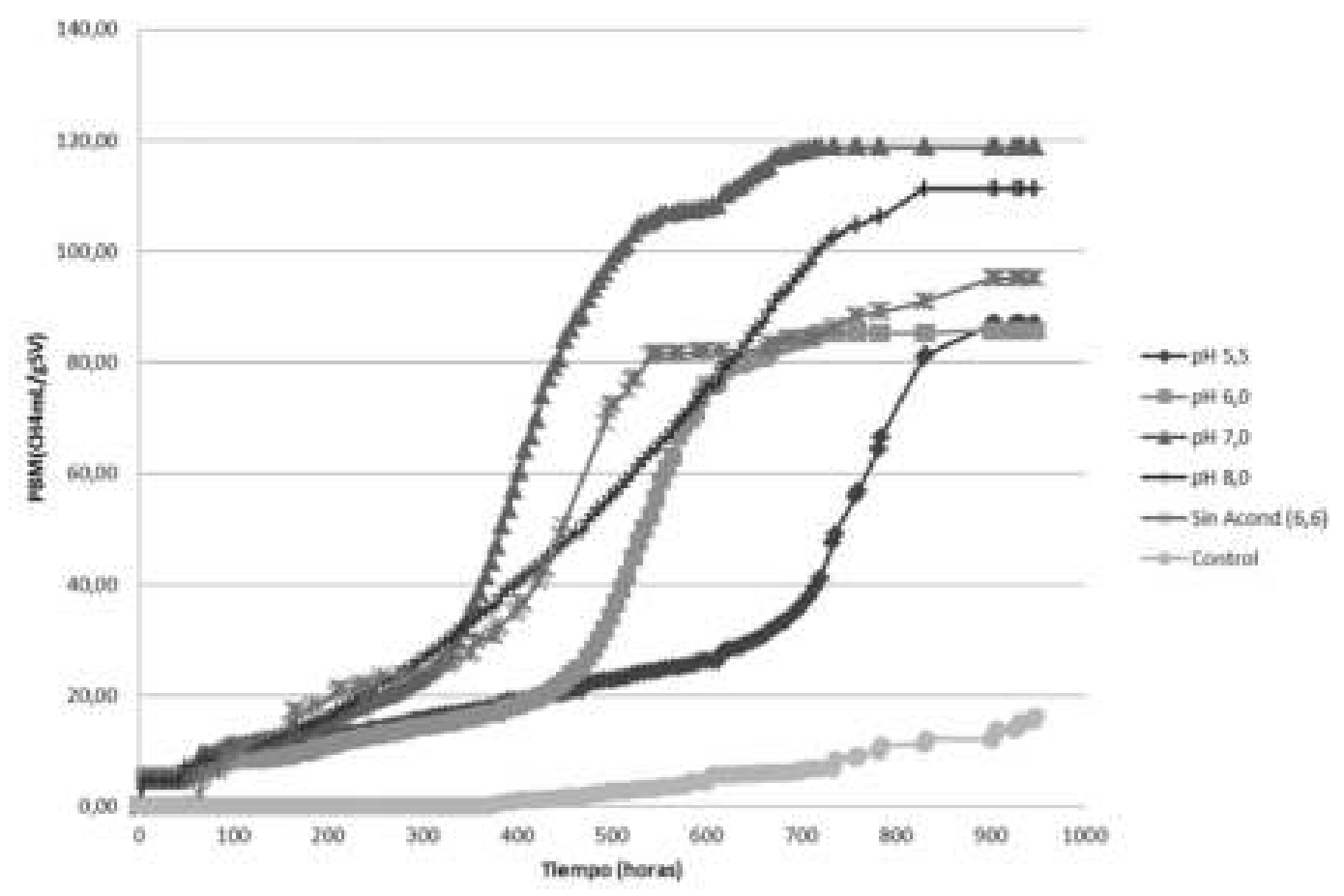

Figura 2. PBM para cada uno de los valores de $\mathrm{pH}$ evaluados.

Tabla 3. PBM total, disuelto y teórico, \% $\mathrm{CH}_{4}$, y \%B.

\begin{tabular}{|c|c|c|c|c|c|}
\hline $\mathrm{pH}$ & $\begin{array}{c}\mathrm{PBM}_{\text {total }} \\
\left(\mathrm{mLCH}_{4} * \mathrm{gSV}^{-1}\right)\end{array}$ & $\mathrm{PBM}^{*}\left(\mathrm{mLCH}_{4} \mathrm{gSV}^{-1}\right)$ & $\begin{array}{c}\mathrm{PBM}_{\text {teórico }} \\
\left(\mathrm{mLCH}_{4} \mathrm{gSV}^{1}\right)\end{array}$ & $\% \mathrm{CH}_{4}$ & $\% \mathrm{zB}$ \\
\hline 5,5 & $70 \pm 23,55$ & $7,7 \pm 2,59$ & 240,0 & 99,67 & 29,0 \\
\hline 6,0 & $71 \pm 21,20$ & $7,8 \pm 2,33$ & 240,0 & 99,97 & 30,0 \\
\hline 7,0 & $126 \pm 10,60$ & $13,9 \pm 1,09$ & 240,0 & 99,84 & 53,0 \\
\hline 8,0 & $95 \pm 23,55$ & $11,4 \pm 1,24$ & 240,0 & 99,83 & 41,0 \\
\hline $\mathrm{SA}^{* *}$ & $99 \pm 5,83$ & $10,8 \pm 0,52$ & 240,0 & 99,84 & 39,0 \\
\hline Control & $28,06 \pm 16,82$ & $3,2 \pm 1,72$ & N.D & 99,30 & N.D \\
\hline
\end{tabular}

N.D: No determinado;*PBM considerando únicamente el metano disuelto;**Sin Acondicionar (6.6UND)

et al. (2000), quienes encontraron las mejores producciones de metano con $\mathrm{pH}$, entre 6,5 y 7,7 unidades. Debido a que tanto las características del inóculo como del sustrato y las condiciones operacionales afectan el proceso biológico, se ratifica la importancia de definir, para cada caso específico, la condición operacional más favorable (Dinamarca et al. 2003).

La tabla 4 muestra los resultados de pH, AT, ATB, AGV e Índice AI/AP, al inicio y final del proceso.
Se observa que, aunque se registró un incremento del $\mathrm{pH}$ y la AT, la ATB no aumentó de manera proporcional, lo que está asociado a la producción y a la acumulación de los AGV, que consumen alcalinidad bicarbonática y pueden llegar a causar acidificación, lo que conlleva a una inhibición de los consorcios microbianos. Este comportamiento ratifica la importancia de controlar la digestión anaerobia, no sólo con el $\mathrm{pH}$, sino también con la alcalinidad en sus diferentes formas, para identificar ocurrencia de condiciones de capacidad buffer y neutralización de la acidez (Torres \& Pérez, 2008). 
Tabla 4. Valores de pH, AT, ATB, AGV y Al/AP al inicio y final del proceso.

\begin{tabular}{|c|c|c|c|c|c|c|c|c|c|}
\hline $\mathrm{pH}(\mathrm{I})$ & $\mathrm{pH}(\mathrm{F})$ & AT $(\mathrm{I})$ & AT $(\mathrm{F})$ & ATB $(\mathrm{I})$ & ATB $(\mathrm{F})$ & AGV's $(\mathrm{I})$ & AGV's (F) & AI/AP (I) & AI/AP(F) \\
\hline 5,5 & 7,95 & 146,03 & 1327,89 & 25,28 & 628,82 & 913,09 & 2001,30 & 4,78 & 1,87 \\
\hline 6,0 & 9,27 & 239,65 & 1766,04 & 66,80 & 1104,74 & 938,11 & 1863,71 & 2,59 & 0,60 \\
\hline 7,0 & 8,21 & 418,98 & 1506,45 & 282,71 & 981,42 & 963,12 & 1419,67 & 0,48 & 0,54 \\
\hline 8,0 & 8,44 & 1586,61 & 2109,49 & 1130,64 & 1466,17 & 1244,56 & 1288,34 & 0,40 & 0,44 \\
\hline $\mathrm{SA}$ & 7,87 & 284,25 & 871,77 & 129,90 & 447,03 & 963,12 & 1544,75 & 1,19 & 0,96 \\
\hline
\end{tabular}

I: Inicial; F: Final; AT y ATB en mg $\mathrm{CaCO}_{3} * \mathrm{~L}^{-1}, \mathrm{AGV}^{\prime} \mathrm{s} \mathrm{mg}^{*} \mathrm{~L}^{-1}$

En general, esta investigación permite concluir que los BOM estudiados presentan una composición predominante de materia orgánica favorable, para un buen desempeño del proceso biológico anaerobio; no obstante, los bajos niveles de $\mathrm{pH}$ y alcalinidad bicarbonática, ligado a las altas concentraciones de AGV, indican la necesidad de acondicionar el sustrato con un alcalinizante.

En este estudió, se mostró que el pH tiene efecto sobre la digestión anaerobia de los BOM, encontrándose mejores condiciones, tanto de producción de metano como de capacidad buffer, con valores cercanos a la neutralidad; valores menores, además de generar menor producción de metano, requieren un mayor tiempo de asimilación de la materia orgánica por parte de los microorganismos, lo que implicaría prolongados tiempos de retención y mayores volúmenes de reactores.

El posible fenómeno de inhibición ocurrido a pH ácidos puede estar asociado a la alteración de la etapa hidrolítica, ya que de esta fase de la DA depende el éxito de degradación de la materia orgánica y, por ende, en la producción de metano. Por lo tanto, se debe buscar una relación $\mathrm{S} / \mathrm{I}$ y pH, en la cual, se den condiciones favorables, que garanticen estabilidad, durante el proceso de transformación del sustrato.

Agradecimientos: Los autores agradecen a la Cooperativa de Servicios Públicos de Versalles, Camino Verde APC y a EMCALI EICE ESP, por el apoyo brindado para el desarrollo de este estudio. Conflicto de Interés: Certificamos la originalidad y el carácter inédito del manuscrito elaborado y revisado, con la participación de todos los autores, quienes declaramos que no existe conflicto de intereses, que ponga en riesgo la validez de los resultados. Financiación: Esta investigación fue financiada por la Universidad del Valle, en el marco del proyecto de convocatoria interna "Evaluación del Potencial de Producción de Energía a partir de la Digestión Anaerobia de Biorresiduos de Origen Municipal-Cl 2704".

\section{BIBLIOGRAFÍA}

1. ABDULKARIM, B. I.; ABDULLAHI, M. E. 2010. Effect of buffer $\left(\mathrm{NaHCO}_{3}\right)$ and waste type in high solid thermophilic anaerobic digestion. Int. J. Chemtech. Res. 2(2):980-984.

2. ACOSTA, Y.L.; ABREU, M.C.O. 2005. La digestión anaerobia. Aspectos teóricos. Parte I. Revista ICIDCA. Sobre los derivados de la caña de azúcar. 39(1):35-48.

3. AGUILAR, V.Q.; ARMIJO, D.V.C.; TABOADA, G.P. 2009. El potencial energético de los residuos sólidos municipales. Ingeniería. 13(1):59-62.

4. ALMEIDA, A.; NAFARRATE, R.E.; ALVARADO, A.; CERVANTES, O.A.; LUEVANOS, M.P.E.; OROPEZA, R.; BALAGURUSAMY, N. 2011. Expresión genética en la digestión anaerobia: Un paso adelante en la comprensión de las interacciones tróficas de esta biotecnología. Acta Quím. Mex. 3(6):14-34.

5. ANGELIDAKI, I.; ALVES, M.; BOLZONELLA, D.; BORZACCONI, L.; CAMPOS, J.L.; GUWY, A.J.; KALYUZHNYI, S.; JENICEK, P.; VAN LIER, J.B. 2009. Defining the biomethane potential (BMP) of solid organic wastes and energy crops: A proposed protocol for batch assays. Water Sci. \& Techn. 59(5):927-934.

6. ANGELIDAKI, I.; ELLEGAARD, L.; AHRING, B.K. 2003. Applications of the anaerobic digestion process. Adv. Biochem. Eng./Biotechn. 82:1-33.

7. APHA. 2005. Standard Methods for Examination of Water and Wastewater. In: FEDERATION, A. W. W. A. A. W. E. (ed.) 21 ed. Washington D.C.282p.

8. AQUINO, S.F.; CHERNICHARO, L.C.A.; FORESTI, E.; FLORENCIO, D.S.M.D.L. 2007. Metodologias para 
determinação da atividade metanogênica específica (Ame) em lodos anaeróbios. Eng. Sanit. Ambient. 12:192-201.

9. BUENROSTRO, O.; BERNACHE, G.; CRAM, S.; BOCCO, G. 2000. Análisis de la generación de residuos sólidos en los mercados municipales de Morelia, México. Rev. Int. Contam. Ambient. 15(1):27-32.

10. CASTELLS, X.E. 2012. Métodos de Valorización y Tratamiento de Residuos Municipales. Reciclaje de Residuos Industriales. Ed. Díaz De Santos. 866p.

11. CHEN, X.; ROMANO, R.T.; ZHANG, R. 2010. Anaerobic digestion of food wastes for biogas production. Int. J. Agric. \& Biol. Eng. 3(4):61-71.

12. DELFÍN, A.I.; DURÁN, D.B.C. 2003. Biodegradación de residuos urbanos lignocelulósicos por Pleurotus. Rev. Int. Contam. Ambient. 19(1):37-45.

13. DINAMARCA, S.; AROCA, G.; CHAMY, R.; GUERRERO, L. 2003. The Influence of $\mathrm{pH}$ in the hydrolytic stage of anaerobic digestion of the organic fraction of urban solid waste. Water Sci. \& Techn. 48(6):294-254.

14. FIELD, J. 1987. Arranque y Operación de Sistemas de Flujo Ascendente con Manto de Lodo-USSB. Universidad del Valle, CVC, Universidad Agrícola de Wageningen. 57p.

15. GONZÁLEZ, G.I.; RUSTRIÁN, E.; HOUBRON, E.; ZAMORA, A. 2008. Impacto de la tasa de humedad en la biodegradación de los residuos sólidos urbanos de la ciudad de Veracruz, México. Rev. Latinoam. Recursos Nat. 4(3):336-341.

16. GIMÉNEZ, J.B.; MARTÍ, N.; FERRER, J.; SECO, A. 2012. Methane recovery efficiency in a submerged anaerobic membrane bioreactor (SAnMBR) treating sulphate-rich urban wastewater: Evaluation of methane losses with the effluent. Biores. Techn. 118:67-72.

17. ICONTEC. 2004. Norma Técnica Colombiana 5167. Productos para la Industria Agrícola, Productos Orgánicos Usados como Abonos o Fertilizantes y Enmiendas de Suelo. 32p.

18. ICONTEC. 2009. Norma Técnica Colombiana 1369. Determinación de Boro, Calcio, Cobalto, Cobre, Hierro, Magnesio, Manganeso, Molibdeno, Níquel, Silicio y Zinc por Absorción Atómica. 3p.
19. LI, R.; CHEN, S.; LI, X. 2010. Biogas production from anaerobic co-digestion of food waste with dairy manure in a two-phase digestion system. Appl. Biochem. Biotechn. 160(2):643-654.

20. MUKHERJEE, S.; KUMAR, S.; DEVOTTA, S. 2008. Influence of nitrogen of anaerobic digestion of municipal solid waste in a laboratory scale reactor. J. IPHE. 9(4):19-24.

21. OVIEDO, O.E.R.; MARMOLEJO, R.L.; TORRES, L.P. 2014. Influencia de la frecuencia de volteo para el control de la humedad de los sustratos en el compostaje de biorresiduos de origen municipal. Rev. Int. Contam. Ambient. 30(1):91-100.

22. PARAWIRA, W.; MURTO, M.; ZVAUYA, R.; MATTIASSON, B. 2004. Anaerobic batch digestion of solid potato waste alone and in combination with sugar beet leaves. Renew. Energy. 29:1811-1823.

23. PERES, C.S.; SANCHEZ, C.R.; MATUMOTO, C.; SCHMIDELL, W. 1992. Anaerobic biodegradability of the organic components of municipal solid wastes (OFMSW). Water Sci. \& Techn. 25(7):285-934.

24. RAPOSO, F.; BANKS, C.J.; SIEGERT, I.; HEAVEN, S.; BORJA, R. 2006. Influence of inoculum to substrate ratio on the biochemical methane potential of maize in batch tests. Process Biochem. 41:1444-1450.

25. SAKURAI, K. 2000. Método Sencillo del Análisis de Residuos Sólidos. CEPIS. Lima-Peru: CEPIS/OPS. 10p.

26. SANDOVAL, C.J.; CARREÑO, M.; CASTILLO, E.F.; VERGARA, M.M. 2007. Caracterización microbiológica de lodos anaerobios utilizados en el tratamiento de la fracción orgánica de los residuos sólidos urbanos. Sci. et Techn. 13(35):509-514.

27. SHARMA, K.S.; MISHRA, I.M.; SHARMA, M.P.; SAINI, J.S. 1988. Effect of particle size on biogas generation from biomass residues. Biomass. 17:251-263.

28. SOBOTKA, M.; VOTRUBA, J.; HAVLÍK, I.; MINKEVICH, I.G. 1983. The mass-energy balance of anaerobic methane production. Folia Microbiol. 28(3):195-204.

29. SUNDBERG, C.; FRANKE, W.I.H.; KAUPPI, S.; YU, D.; ROMANTSCHUK, M.; INSAM, H.; JÖNSSON, $\mathrm{H}$. 2011. Characterisation of source-separated household waste intended for composting. Biores. Techn. 102(3):2859-2867. 
30. TORRES, L.P.; PÉREZ, A. 2008. Índices de alcalinidad para el control del tratamiento anaerobio de aguas residuales fácilmente acidificables. Ingen. y Competitiv. 10(2):41-52.

31. TORRES, L.P.; PÉREZ, A. 2010. Actividad metanogénica específica: Una herramienta de control y optimización de sistemas de tratamiento anaerobio de aguas residuales. Rev. EIDENAR. 9:5-14.
32. TWB. 2012. World production of Municipal Solid Waste (MSW), 2012-2025. The World Bank. p.16-17.

33. VEEKEN, A.; KALYUZHNYI, S.; SCHARFF, H.; HAMERLERS, B. 2000. Effect of pH and VFA on hydrolysis of organic solid waste. J. Environm. Eng. 126(12):1076-1081.

Recibido: Abril 16 de 2014

Aceptado: Agosto 27 de 2014

Como citar:

Parra-Orobio, B.A.; Torres-Lozada, P.; Marmolejo-Rebellón, L.F.; Cárdenas-Cleves, L.M.; Vásquez-Franco, C.; Torres-López, W.A.; Ordoñez-Andrade, J.A. 2014. Influencia del pH sobre la digestión anaerobia de biorresiduos de origen municipal. Rev. U.D.C.A Act. \& Div. Cient. 17(2): 553-562. 